\title{
FACEBOOK AS A MEDIATION TOOL IN BIOCHEMISTRY DISCIPLINE
}

\author{
Gomes, P.X. ${ }^{1}$, Pinho, T.S. ${ }^{1}$, Hornink, G.G. ${ }^{2}$ \\ ${ }^{1}$ Biomedicine undergraduate course, Federal University of Alfenas, Minas Gerais, \\ Brazil; ${ }^{2}$ Biochemistry Departament, Biomedical Institute, Federal University of Alfenas, \\ Minas Gerais, Brazil
}

Introduction: The current students generation are daily connected to the Internet, wich encourages the use of mobile tools in education. Many of the students of Biochemistry feel apprehensive about the discipline and the use of facebook may contribute, among other factors, motivating them. Objectives: It was analyzed the use of facebook as a mediator and motivator in the discipline of Biochemistry, basing on socioconstrutivist interventions. Material and methods: This work was developed in the action-research perspective, using the quali-quantitative method. An investigative questionnaire was used, using Likert scale and open questions, to investigate the facebook use, as well as the preferences of students, focusing on Biochemistry group in the Biomedicine course. The posts were analyzed identifying: frequency of the interaction`s types (post, comment, likes); interaction's categories (question, answer, motivational); and the content itself of the post. Results: It was highlighted students' interest to search materials, answering questions, and especially seeking information about the discipline. It was emphasized that the group was motivating for learning Biochemistry, encouragement the group to study, with quick and easy access to the professor by chat. Conclusions: The results indicate a preference for students at facebook, with a great motivational potential, is at easy access to colleagues, professor and monitor, or even the ease of obtaining the materials and ask questions in real time, indicating that this tool as a possible way, still little explored, to enhance the teaching of Biochemistry.

Keywords: Facebook, Biochemistry teaching-learning, social web

Acknowledgements: FAPEMIG 